\title{
MAJOR TEN PARAMETERS OF PULSATING HEAT PIPE- A REVIEW
}

\author{
Bukke Nagamuni Naik ${ }^{1}$, Pramod R. Pachghare ${ }^{2}$ \\ ${ }^{1}$ Department of Mechanical, Government College of Engineering, Amravati, India \\ ${ }^{2}$ Assistant Professor, Government College of Engineering, Amravati, India \\ Email: ${ }^{[1]}$ nagamuni08@gmail.com, ${ }^{[2]}$ pramod.pachaghare@gmail.com
}

\begin{abstract}
Thermal Management in the present issue in the modern era. The technology in heat transfer day by day is increased gradually especially in electronic device, space applications, hybrid vehicles, solar heater. These are the major areas where heat management are successfully research is going on Pulsating Heat Pipe is a two phase device where the heat transfer is takes place through sensible and latent heat. This paper gives an over review of the Pulsating heat pipe design, working principle, parameters which effects the PHP, dryout condition and applications where PHP is used successfully research is going on. This paper addresses the fundamentals of PHP, an overview, and the applications of PHP.
\end{abstract}

Keywords: pulsating heat pipe, applications, thermal management

\section{Introduction}

Heat Pipe is a device to transfer the heat from place to another through a copper pipe and is discovered by R. S. Gaugler [1]. Pulsating heat pipe invention and design by Akachi [2-4]. Pulsating heat pipe is the new family of heat pipe with a simple design, low cost, no vibrating equipment's. There are very few devices where the formation of bubbles, condensation, pumping action, bubbles combination dynamic instabilities, non-equilibrium all these formation in a small dives. The phenomenon of two phase flow are following many industries, steam generators, chemical units.

Pulsating heat pipe is a facile device consists of three sections. Evaporator section where heat is to be addition and bubbles formation takes place, Condenser section where heat rejection and bubbles collapse takes place, Adiabatic section where there is no heat transfer existence takes place. Construction of pulsating heat pipe is of two types. (1) Closed Loop Pulsating Heat Pipe, (2) Open Loop Pulsating Heat Pipe. Both Closed and Open Loop Pulsating Heat Pipe is in serpentine type of structure. If desition (end) joints are ended then it is called as CLPHP if desition (end) joints are open then it is called as OLPHP. Figure 1. Are the types are shown below. PHP is a device that performs continuously heat transfers through sensible heating and latent heating by evaporation and condensation caused by changing the temperature differences. Based on the past experiments [5] explained about the behaviour of mixture of fluids and studies major experimental fluids are water, methanol, acetone, ethanol, r134a. For cryogenic applications helium and hydrogen gas are major fluid. Self-retrieving fluids [6]. Some working fluids shown more thermal resistance because of the thermal properties. Before starting the experiments the CLPHP is evacuated and filled with some percent of working fluid. Parameters effecting php [7-8], explains well.

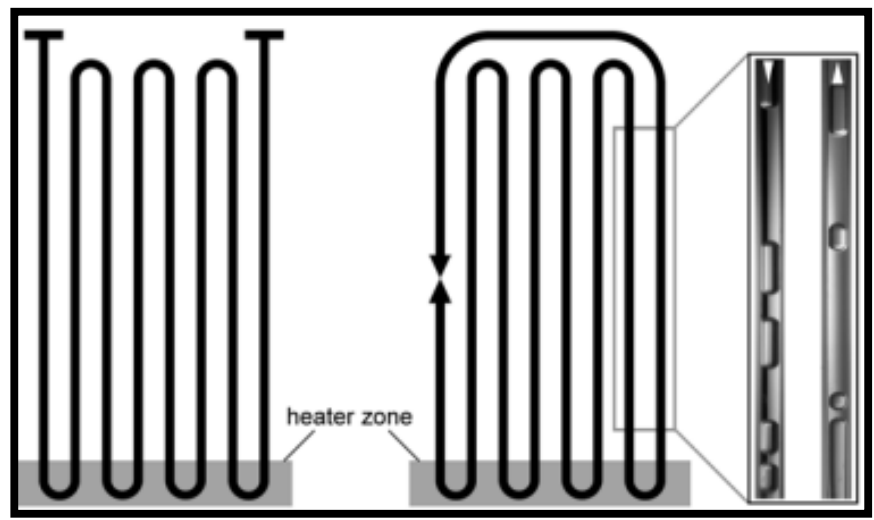

Fig.1 Open and Closed PHP

\section{Parameters Effecting PHP:}

There are many parameters which effects PHP. In that mainly effects the PHP discussed.

2. Tube Material with working fluid:

Table 1. For working fluid and tube material

\begin{tabular}{|l|c|c|c|}
\hline \multirow{2}{*}{ Tube Material } & \multicolumn{3}{|c|}{ Working Fluid } \\
\cline { 2 - 4 } & Water & Acetone & Ammonia \\
\hline Copper & RU & RU & RU \\
\hline Aluminium & GCN & RL & RU \\
\hline Stainless Steel & GCN & MC & RU \\
\hline Nickel & MC & MC & RU \\
\hline
\end{tabular}

RU- recommended by past successful usage,

RL- recommended by literature,

MC- may compatible,

GNC- generation of gas all temperatures. 
The above table explains about the tube material and working fluid relation, weather the tube is sufficient used the working fluid or not.

\section{Tube Diameter:}

Tube internal diameter plays a major role in PHP. It based on critical Bond number (Bo) or Eötvös (Eö) relation given as

$$
\begin{aligned}
B_{O} & =D_{c r i} \times \sqrt{\frac{g\left(\rho_{l}-\rho_{v}\right)}{\sigma}} \\
\text { Ё̈ }=[\mathrm{Bo}]^{2} & =4
\end{aligned}
$$

Where $\sigma=$ working fluid surface tension $(\mathrm{N} / \mathrm{m}) ; \mathrm{g}=$ gravitational acceleration $\left(\mathrm{m} / \mathrm{s}^{2}\right) ; \rho_{\mathrm{l}}=$ liquid density $\left(\mathrm{Kg} / \mathrm{m}^{3}\right) \rho_{\mathrm{v}}$ = vapor density $\left(\mathrm{Kg} / \mathrm{m}^{3}\right) \mathrm{D}=$ diameter of the tube

There are four possible cases are formed in PHP. If D $\ll D_{\text {cri }}$ means diameter is very small then the losses of dissipative and low thermal performances. If $\mathrm{D}>>>\mathrm{D}_{\text {cri }}$ means greater diameter then critical diameter there will be phenomenological performance on the device. There will be no more pulsation of bubbles and collapse of the bubbles. So prefer $\mathrm{D}_{\text {cri }}=\mathrm{D}$ internal diameter $[13]$.

\section{Total Number of Turns:}

The quantity of turns in the PHP may influence warm execution making irrelevant the impact of gravity. Even by increasing number of turns, increase in quality of working fluid, there will be more heat turbulence in capillary tube and there will be more pressure drop in condenser and evaporator section. Based on past research two turn PHP is better preferred [12][14].

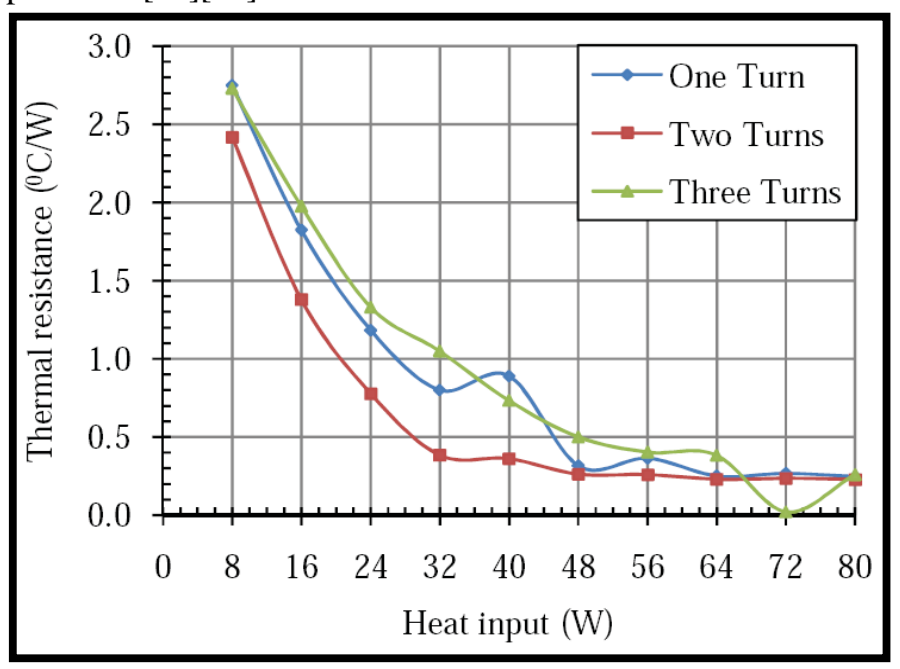

Fig.2 Number of turns is preferred

\section{Orientation of PHP:}

One of the parameter which effects to the good thermal performances is orientation. Two parameters are included in it. Gravity and Total number of turns. For changing the orientation the compared to horizontal and vertical. All the research are suggest that all the good thermal performances vertical orientation is preferred. A combination of large in number of turn and high heat input shows the continuous operation in all orientations. In all the views 50-65 degrees gives the best thermal resistance.

\section{Design of Condenser and Evaporator Sections:}

Design of Condenser and Evaporator are the important parameter in PHP which effects the thermal performance. In order to avoid dry out condition the evaporation length is smaller then condenser. If the heat input is increases the evaporator and condenser temperature is increases. If the length of evaporator is more than condenser then the rate of heat rejection is less and the temperature in the capillary tube increases that leads to evaporation. If the evaporator length is less than condenser length then the rate of heat rejection is more and the temperature in the php will decreases that leads to work continuously without dry out condition [10].

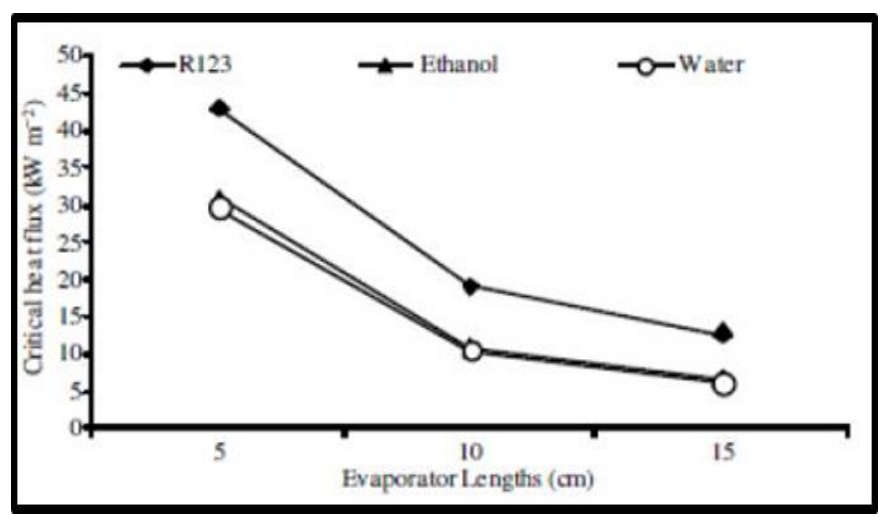

Fig.3. Designed length of Evapotator

\section{Bend Effect:}

In Php the geometry will be in number of turns. There will be $90 \mathrm{o}$ and $180 \mathrm{o}$ that bent leads to decrease the local pressure. When the bubble is reached evaporator to condenser section then the bubble take diversion at the bend while it takes to turn rotate there will be decrease in speed and that leads to decrease the pressure. When the bubbles completion of rotation and comes down as fastly with gravity that leads the increase in local pressure.

\section{Filling Ratio:}

Filling ratio is defined as the volume of fraction of the fluid is filled in the PHP, initially filled and then sealed at the room temperature. If the Filling ratio is 0 means there is no working fluid in PHP and is known as dry out condition. If the filling ratio is 1 then the PHP is fulled with working fluid. If there is no working fluid it has high thermal resistance. A fully filled CLPHP acts as a single thermosyphone in that there will no bubbles, no pulsating for some time. After some time a few 
bubbles were generated but those bubbles did not required to circulate and formation of perturbations and very low degree of freedom. In this case there will be lot of time to comes dry out condition.[9]

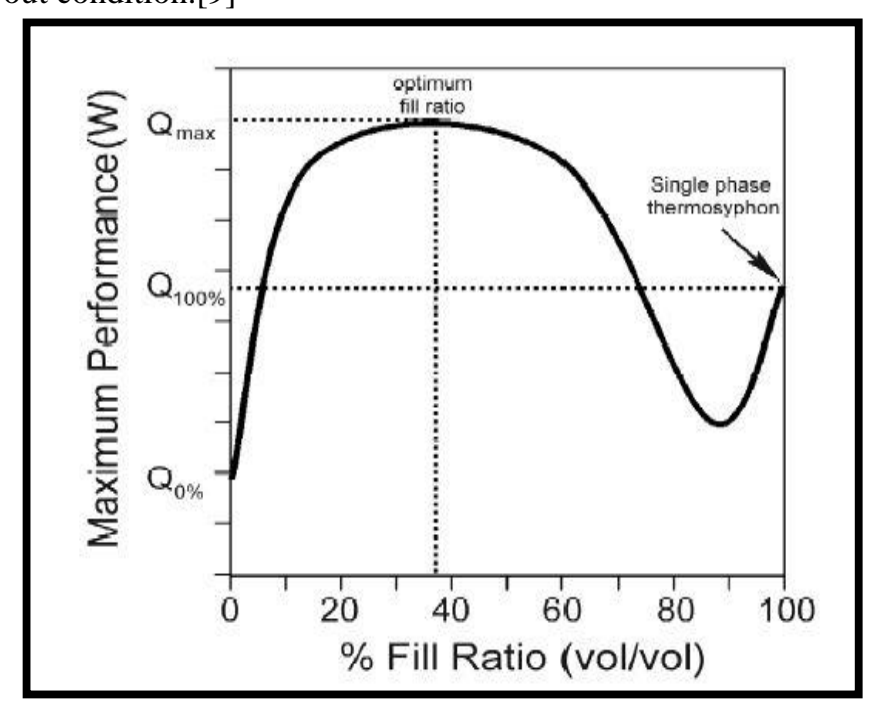

Figure 4. Maximum Filling Ratio

For the based on the past research only 40 to $60 \%$ gives the best thermal performance.

\section{Heat Flux:}

The working fluid has different properties based on the characteristics the heat flux will very. Heat flux done many things in PHP.

- Starts the Pulsating

- Breaks the pattern of the system

- Flow instability

- perturbations

- Slug flow to semi annular and annular flows.

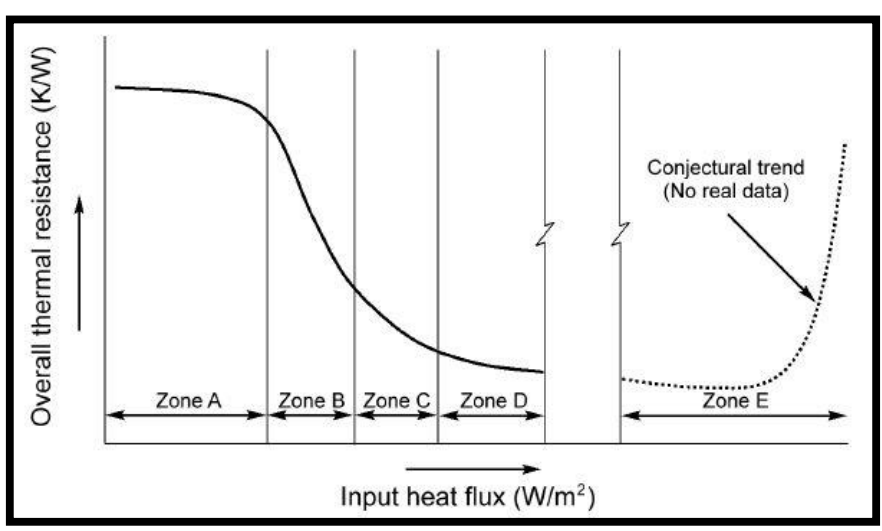

Figure: 5 Effect of input heat flux

Zone A: Low Oscillation

Zone B: Slug Flow Oscillation

Zone C: Slug Flow in a particular direction

Zone D: Slug flow to Annular Flow in a particular direction

Zone E: Near Dry out condition

\section{Dry Out Condition:}

Dry out condition means there is no fluid in CLPHP. The total fluid is evaporates and condenser is totally vaporized. For this condition there are many reasons. Main conditions occurring of Dry out condition is total length of the evaporator is more than condenser and another factor is low filling ratio. When the filling ration is small then also there will cause of dry out condition. Another factor is giving high heat input. Whenever there is high heat input and low filling ratio this combination have major chances to dry out condition. Once the total dry out condition comes the heat transfer takes place by conduction.

\section{Physical Properties of a working fluid:}

Choosing the working fluid is very important factor because all the performance is based on working fluid only. There are few parameters that has consider while selecting the fluid,

Viscosity: Low viscosity decreases the pressure drop in php that leads increase the oscillating speed in PHP. Surface tension: High surface tension increases the maximum diameter of the PHP. Specific heat: High specific heat of liquid increases the amount of energy the liquid can carry in the form of slug flow. Latent heat: High latent heat in the PHP increases the amount of energy passes via phase change in the form of vapour plugs. High Latent heat transfer more heat transfer that leads to be good PHP. Density: Low density of the liquid phase decreases the effect of gravity. Freezing Point: There will be no point of freezing in PHP till now of all the journals because the heat input and the bubble flowing and transfer of heating process is continuously. Hence the temperature of freezing is some high temperature is preferred.

Some of the Fluids used in PHP and properties of the fluids are given in table 2 :

\begin{tabular}{|c|c|c|c|}
\hline $\begin{array}{c}\text { Working } \\
\text { Fluid }\end{array}$ & $\begin{array}{c}\text { Melting } \\
\text { point }\end{array}$ & $\begin{array}{c}\text { Boiling } \\
\text { point }\end{array}$ & Useful range \\
\hline Helium & -271 & -261 & -271 to -269 \\
\hline Nitrogen & -210 & -196 & -203 to -160 \\
\hline Ammonia & -78 & -33 & -60 to 100 \\
\hline Acetone & -95 & 57 & 0 to 120 \\
\hline Methanol & -98 & 64 & 10 to130 \\
\hline Ethanol & -112 & 78 & 0 to130 \\
\hline Heptane & -90 & 98 & 0 to150 \\
\hline Water & 0 & 100 & 30 to200 \\
\hline
\end{tabular}




\section{Applications of PHP:}

Based on the research these are some real time applications used in PHP.

$>$ Cooling System For Electric Vehicle Li-Ion Batteries

$>$ Chimney Heat Recovery

$>$ Air-Conditioning System

$>$ Fuel Cell Cooling

$>$ Hybrid Vehicle Applications

$>$ NARX Neural Networks

$>$ Printed Circuit Board (PCB)

$>$ PC Cooling

$>$ Solar Panel Cooling

$>$ Stirling Cooler

\section{Conclusions:}

A closed loop Pulsating heat pipe has investigated to study the effects of various parameters like tube material, capillary tube inner diameter, number of turns, orientation, condenser and evaporator lengths, Filling ratio and Properties of working fluids. These are the major factors that effects the PHP. Meanwhile the research is going on the other side like industries, solar panel cooling, chimney heat recovery, hybrid vehicles are some of the examples. Closed loop Pulsating Heat pipe is also used in cryogenics, electronics cooling. In all the aspects PHP is the best device to transfer the heat by its design, cost effective, working mechanism. Near dryout condition there will be need of research in my point of view. There are many issues regarding working fluid but it still need research, further exploration takes a challenging to solve.

\section{References}

[1] Grover, G. M., Cotter, T. P. and Erikson, G. F., 1964 "Structures of Very High Thermal Conductivity", $J$. Appl. Phys., 35, 1990

[2] Akachi, H., 1990, "Structure of a heat pipe," U.S. Patent $4,921,041$.

[3] Akachi, H., 1994, "Looped Capillary Heat Pipe," Japanese Patent No. 697147.

[4] Akachi, H., Polášek, F., Štulc, P., 1996. "Pulsating Heat Pipes," Proceedings of the 5th International Heat Pipe Symposium, 208-217.

[5] P. Pachghare, M. Mahalle, 2012 "Thermal performance of closed loop pulsating heat pipe using pure and binary working fluids," Frontiers in Heat Pipes (FHP), 3, 03300 .

[6] Y. Hu, T. Liu, X. Li, S. Wang, 2014," Heat transfer enhancement of micro oscillating heat pipes with selfrewetting fluid," International Journal of Heat and Mass Transfer, 70, 496-503.

[7] Charoensawan, P., Khandekar, S., Groll, M., Terdtoon, P., 2003, "Closed loop pulsating heat pipes Part A: parametric experimental investigations," Applied Thermal Engineering, 23, 2009-2020.

[8] Khandekar, S., Charoensawan, P., Groll, M., Terdtoon, P., 2003, "Closed loop pulsating heat pipes Part B: visualization and semiempirical modeling," Applied Thermal Engineering, 23, 2021-2033.

[9] Khandekar S., Dollinger N. and Groll M., Understanding Operational Regimes of Pulsating Heat Pipes: An Experimental Study, Applied Thermal Engineering, Elsevier Science, (2003)

[10] J. Wang, H. Ma, Q. Zhu, 2015, Effects of the evaporator and condenser length on the performance of pulsating heat pipes, Applied Thermal Engineering 91, 1018-1025.

[11] Pachghare, P., Mahalle M., Khedkar, S., 2012, "Effect of Working Fluid on Thermal Performance of Closed Loop Pulsating Heat Pipe: A Review," International Journal of Computer Applications, 9, 27-31.

[12] Mamelli M., Marengo M. and Zinna S.,2011, Numerical model of a multi-turn Closed Loop Pulsating Heat Pipe: Effects of the local pressure losses due to meanderings, Journal of Heat and Mass Transfer, 55, 1036-1047.

[13] Khandekar, S. and Groll, M., 2003, "On the Definition of Pulsating Heat Pipe," Proc. 5th Minsk International Seminar (Heat Pipes, Heat Pumps and Refrigerators), Minsk, Belarus.

[14] Rahul S. Borkar, P. Pachghare, 2015, "Effect Of Working Fluid, Filling Ratio And Number Of Turns On Pulsating Heat Pipe Thermal," Frontiers in Heat Pipes (FHP), 6,4. 
